\title{
A Simple Model of the Difference Principle
}

\author{
Takashi Suzuki \\ Department of Economics, Meiji-Gakuin University, Tokyo, Japan \\ Email: takashisuz@jcom.home.ne.jp
}

How to cite this paper: Suzuki, T. (2018) A Simple Model of the Difference Principle. Theoretical Economics Letters, 8, 1869-1888. https://doi.org/10.4236/tel.2018.810123

Received: March 24, 2018

Accepted: June 18, 2018

Published: June 21, 2018

Copyright (C) 2018 by author and Scientific Research Publishing Inc. This work is licensed under the Creative Commons Attribution International License (CC BY 4.0).

http://creativecommons.org/licenses/by/4.0/

\begin{abstract}
In this paper, we present a socioeconomic model illustrating the difference principle first proposed by John Rawls (1971). We demonstrate that this principle can be fulfilled by incorporating reciprocity into the basic structure of society. We show its appropriate embodiment in external increasing returns in line with traditional neoclassical economic theory, which is the exact mechanism described by Rawls $(1971,2001)$. Our model yields an intuition and interpretation of the principle by showing its implementation in the market equilibrium. Moreover, the model will show that the utilitarian principle, i.e., the maximization of the total (average) utility leads to advantaged people monopolizing all wealth as a just state of society. We also discuss the sociopolitical conditions necessary for the difference principle model to be stable and sustained.
\end{abstract}

\section{Keywords}

Justice as Fairness, Difference Principle, Reciprocity, External Increasing Returns

\section{Introduction}

John Rawls [1] proposed and established the difference principle as an alternative to the utilitarian principle in social justice. The difference principle states that:

Social and economic inequalities are to be arranged so that they are attached to the greatest benefit of the least advantaged ([1], p. 83).

Rawls [2] listed up to five kinds of social regimes: a) laissez-faire capitalism ${ }^{1}$; b) welfare-state capitalism; c) state socialism with a command economy; d) property-owing democracy; and e) liberal (democratic) socialism. Rawls asked himself:

${ }^{1}$ A regime supported by Hayek [3] and Nozick [4]. 
When a regime works in accordance with its ideal institutional description, which of the five regimes satisfy the two principles of justice? ([2], p. 137).

This question is significant, especially as Rawls observed:

[W] hile a regime may include institutions explicitly designed to realize certain values, it still may fail to do so. Its basic structure may generate social interests that make it work very differently than its ideal description (ibid., p. 137).

Rawls eliminated the first three regimes (a) to (c) because he felt that they violated the principles of justice from the outset and concluded:

This leaves (d) and (e) above, property-owing democracy and liberal socialism: their ideal description include arrangements designed to satisfy the two principles of justice (ibid., p. 138).

However, we note that Rawls did not provide any positive or convincing proof to demonstrate that the second principle was indeed satisfied within (at least) these two regimes. Thus, the purpose of this paper is to provide a proof that supports his conclusion.

The absence of proof is no accident. Indeed, Rawls would not be able to prove his conclusion even if he had attempted to do so because he did not have any theoretical understanding of the underlying mechanism ${ }^{2}$, including how the difference principle is realized by the economic and political institutions in property-owing democracy (d) or liberal socialism (e).

Consider Figure 1, which corresponds to Figure 6 in Rawls ([1], p. 76). As far as we are aware, this is the only exposition by Rawls that elaborates upon the difference principle theoretically.

Rawls explained this as follows:

Suppose that $x_{1}$ is the most favored representative man in the basic structure. As his expectations are increased so are the prospects of $x_{2}$, the least advantaged man. In Figure 6 [our Figure 1] let the curve OP represent the contribution to $x_{2}$ 's expectation made by the greater expectations of $x_{1}$. The point $\mathrm{O}$, the origin, represents the hypothetical state in which all social primary goods are distributed equally. Now the OP curve is always below the $45^{\circ}$ line, since $x_{1}$ is always better off. Thus the only relevant parts of the indifference curves are those below this line, and for this reason the upper left-hand part of Figure 6 is not drawn in. Clearly the difference principle is perfectly satisfied only when the OP curve is just tangent to the highest indifference curve it touches. In Figure 6 this is at the point $a([1]$, p. 76$)$.

However, the question is where does the contribution curve OP come from? In [1], the mechanism that generates this curve is a black box, which is precisely what we wish to explore in the remainder of this paper.

Thus, the clue is the concept of reciprocity as described by Rawls:

${ }^{2}$ However, Rawls did have quite a strong intuition. This is evident from the quotation from [2] in the following. 


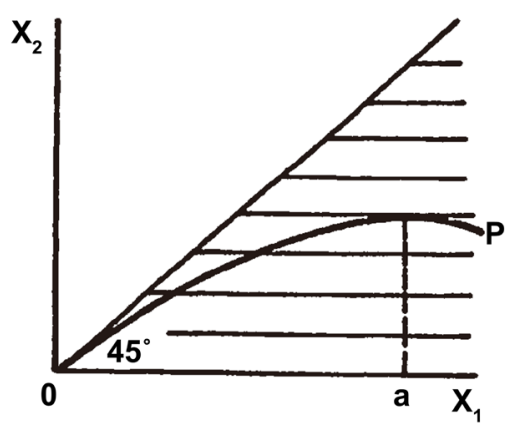

Figure 1. Figure 6 in Theory, p. 76.

[T] he difference principle expresses a conception of reciprocity. It is a principle of mutual benefit (ibid., p. 102).

In the next section, we show that the economic concept of external increasing returns as developed in neoclassical theory expresses reciprocity (mutual benefit), such that a society equipped with external increasing returns can generate the type of contribution curve shown in Figure 1.

In sum, reciprocity is a social relationship of mutual advantage that can be achieved by individually rational behavior ${ }^{3}$. Reciprocity is said to exist in society if a person acts from his/her own interest and this action gives something beneficial to others. In this sense, market trade is an example of reciprocity. However, external increasing returns do more; they increase productivity and expand the entire economy, not just those aimed at allocation efficiency.

The paper is organized as follows. After explaining how the idea of reciprocity or mutual advantage embodied in the difference principle is appropriately expressed by external increasing returns in Section 2, the concept of production functions with external increasing returns is formally defined in Section 3. In Section 4, this concept will be essentially applied in our social model implementing the difference principle. The heart of this paper is Section 5, where we will examine the economic conditions to be satisfied for the difference principle. The political conditions required for the difference principle will be discussed in Section 6. Section 7 concludes.

\section{External Increasing Returns and Reciprocity}

When we refer to external increasing returns, we intuitively mean the increase in ${ }^{3}$ In Rawls [5], the concept of reciprocity is extended into the idea of fair terms of cooperation rather than just mutual advantage:

[A]ll who engaged in cooperation and who do their part as the rules and procedure require, are to benefit in an appropriate way as assessed by a suitable benchmark of comparison ([5], p. $16)$.

However, this finer concept of reciprocity was basically developed from the idea of mutual advantage, even though Rawls remarked that both ideas are not identical ([5], p. 17). The revised concept of reciprocity should then be based on mutually reasonable behaviors rather than just rational ones. We will come back to this point later. 
each firm's productivity resulting from the investments of all firms in the market. This can be achieved not by market trade between firms, but by an external effect from outside the market (hence external increasing returns). We formally present this idea in a more mathematically rigorous manner in the next section. The idea dates back at least to Adam Smith [6] and the division of labor in a pin factory ${ }^{4}$. Indeed, reciprocity can be observed for external increasing returns even in this prototype.

The division of labor increases the productivity of the firm (factory) by dividing tasks and specializing work in the production processes. However, each separate task makes no sense in and of itself. Although each part of the process is conducted by a single worker (or group of workers), all other parts are interdependent. The division of labor then presupposes cooperative relationships between the workers in the factory. We also remark that these cooperative actions are generally not intentionally altruistic or benevolent; rather, they generally result from each person's rational behaviors. Thus, there is a form of mutual advantage or reciprocity within the factory. External increasing returns are then simply the generalization of the reciprocity within the factory to the entire industry and/or the whole economy. We must consider that the problem is not the "efficiency of markets," but of the reciprocity incorporated into liberal societies. In other words, this is not a problem within markets but outside markets, i.e., it is the influence of external factors. The crucial aspect is the basic structure of the liberal societies in which the reciprocity is incorporated. This is exactly what enters our consideration of external increasing returns. Generally, the cooperative relationship in the division of labor is recognized retrospectively. For instance, there are generally no "central planners" in any factory to form relationships between workers. The division of labor is self-organizing; therefore, so are external increasing returns, which do not come from any particular human mind. Thus, the reciprocity embodied in external increasing returns is the work of the institutions in a liberal society, which develop naturally to increase the welfare of the members of the society ${ }^{5}$. In this sense, external increasing returns exist everywhere in a liberal society.

The tendency to form such an institution is because people in any society cannot do everything they want or receive everything they need. Thus, people do what they can do and rely on other people for the rest; i.e., they have natural complementarities with each other. This is exactly what Rawls called a social union. This idea later deeply impressed Kenneth Arrow, who also pointed out its similarity to Adam Smith's pin factory:

Indeed, one of the most brilliant passages in Rawls's book is that on what he calls "social union" ([1], pp. 520-530). He argues that no human life is enough to encounter more than a small fraction of the experiences needed for completeness, so that individuals have a natural complementarity with 
each other (a more mundane version of this idea is Adam Smith's stress on the importance of the division of labor) ([9], p. 262).

Our fundamental argument is that this kind of mechanism could be responsible for the contribution curve OP in Figure 1. Indeed, Rawls himself stated that the increasing portion of the contribution curve arises from the social relationships of mutual advantage (reciprocity), and not just the locus of the redistribution of goods. Instead, Rawls suggested that it results from the cooperative actions among people made possible by the basic structures or institutions of society:

Note that the contribution curve, the curve OP, supposes that social cooperation defined by the basic structure is mutually advantageous. It is no longer a matter of shuffling about a fixed stock of goods ([1], p. 77).

It would be impossible to consider the difference principle using any standard market model lacking this sort of mechanism because the difference principle is reduced to the (average) utilitarian principle in such models. We will expand on this point at a later stage. However, we must stress that a mechanism caused by external increasing returns is an example of reciprocity. We do not assert that it is the mechanism by which the second principle is fulfilled. What we hope to accomplish in this paper is to show how mutual benefits are naturally built into social increasing returns and that they will then give us an intuition how the second principle can be realized in societies characterized by property-owing democracy or liberal socialism.

\section{Production Functions with External Increasing Returns}

In this section, we explain the idea of external increasing returns following Chipman [10], Romer [7], and Suzuki [11] [12]. Suppose that there are two types of commodities: a consumption commodity $x$ and an input commodity $z$. The consumption commodity is produced by firms with a production function in the form $y=f(z ; \zeta)$, where $\zeta$ is a parameter with an economic meaning explained later. The function $f(z ; \zeta)$ is assumed to be homogeneous of degree 1 in $z$, (Hom) $f(\lambda z ; \zeta)=\lambda f(z, \zeta)$ for all $\lambda \geq 0$, and it is monotonically increasing in $\zeta$, (Mon) $f(z ; \zeta) \leq f\left(z ; \zeta^{\prime}\right)$ whenever $\zeta \leq \zeta^{\prime}$.

Given these two conditions, the final outputy is produced under "increasing returns to scale," i.e.:

$$
f(\lambda z ; \lambda \zeta)=\lambda f(z ; \lambda \zeta) \geq \lambda f(z ; \zeta) \text { for all } \lambda \geq 1
$$

The condition (Mon) means that the external effect is positive, which plays a crucial role in this analysis. Through this positive externality, the cooperative arrangements leading to reciprocity in this society will be manifested as shown below. As $\zeta$ is a parameter for each firm, the condition (Hom) implies that the firm subjectively operates under constant returns; therefore, no profits will exist at equilibrium. Thus, the condition (Hom) also plays an important role, which we discuss in the following section. 
Chipman [10], Romer [7], and Suzuki [11] [12] interpreted $\zeta$ as total input $\sum z$, where the summation covers the entire economy. Therefore, this parameter depends on the amount of input used by other firms in the economy; i.e., these increasing returns come from (positive) externalities. For each firm, the value of $\zeta$ is given by the market, and the firm cannot determine it itself.

The most significant difference between this and an ordinary production function is that the function $f(z ; \zeta)$ not only describes the production technology of the firm, but also reflects the background institutions of society. As stated in the previous section, background institutions determine externalities that increase the productivity of each firm, but their interpretation is not specific and is completely open. For instance, Paul Romer interpreted these as a "knowledge spillover effect":

The creation of new knowledge by one firm is assumed to have a positive external effect on the production possibility of the other firms because knowledge cannot be perfectly patented or kept secret. More important, production of the consumption goods as a function of the stock of knowledge and other inputs exhibits increasing returns; more precisely, knowledge may have an increasing marginal product ([7], p. 1003).

The network of information transmissions by which technologies will prevail in society is indeed a typical example of background institutions. It is obvious that the more a society expands, the larger the societal network. The knowledge spillover effect asserts the converse: the formation and growth of the information network will bring mutual advantage to the members of the society, and consequently, will contribute to the prosperity of society. This is a typical mechanism governing how reciprocity works. Undoubtedly, there are many more examples of institutions generating this sort of reciprocity. Of course, we cannot list them all, nor specifically describe each in our theoretical model. Nevertheless, as we show in the next section, it is exactly this type of reciprocity that produces the contribution curve OP in Figure 1.

\section{A Toy Model of Liberal Societies}

In this section, we provide a simple toy model of a society with free markets to provide an interpretation of the difference principle. We stress that this is a model of a liberal society, rather than just an (ordinary) economic market.

As a market model, we show that the difference principle is economically and theoretically possible. However, we do not believe it will be sufficient. We ask if the difference principle will prevail stably in the society. To conclude that this will indeed be the case, some political and legal conditions beyond the (usual) economic conditions (such as consumer rationality) are required. In particular, the conditions that the difference principle is recognized and honored in the society, and that citizens are reasonable rather than merely rational seem crucial. Rawls [5] already emphasized these conditions for well-ordered societies. We will explain these conditions in more detail in the following. 
In this sense, our model serves as a device of representation ${ }^{6}$. We should consider that these are distinct from the description of actual societies and we only construct these to obtain some intuition to help us to explain the reciprocity mechanism underpinning the difference principle. To this end, we present the model as simply possible. Therefore, the "reality" of the model should not be questioned too severely.

In society, two kinds of goods are traded in markets. Consumption goods are consumed by all members of society and its amount is denoted by $x$. Consumption goods determine the current level of quality of life for citizens and lead to expectations for their future lives. The other type of good is input goods, which are used as an input (resource) to produce the consumption good and its amount is denoted by $z$. The input good is not consumed, which means that the consumers' utilities do not depend on it. Therefore, the value of the consumption good can be identified as the utility level if we restrict ourselves within the class of monotonous and continuous utility functions. This allows us to avoid the problem of the interpersonal comparability of utilities. We can also interpret the input good as a primary good in Rawls's sense [1] because it is required to develop each person's life plan; i.e., advantaged citizens will use it as "money" and increase their "productivity" (see below). For simplicity, we assume that there is initially no consumption good in the society (market) and so it must be produced by the social cooperative production activity described as follows.

There are two groups of citizens (consumers). Citizen 1 represents the group of more-advantaged (or talented) persons and citizen 2 represents the group of less-advantaged persons. Here we assume that the populations of the both groups are the same to facilitate a comparison of the results with those of Rawls. However, our results are far more general in this restricted setting because they do not depend on the population ratio of the two groups (see the Appendix).

Citizens 1 and 2's consumption levels are denoted by $x_{1}$ and $x_{2}$, respectively (see the variables $x_{1}$ and $x_{2}$ in Figure 1). Citizens own nothing but possess some amount (possibly 0 ) of the primary good as an initial endowment. Let $\Omega>0$ be the total amount of the primary good that initially exists in society. We denote the share of citizen 1 by $\omega$, therefore, the share of 2 is $\Omega-\omega$. We identify $\omega$ as the index of the policy parameter through which the government arranges justice in the society. When $\omega=\Omega$, then the advantaged person owns all, and when $\omega=0$, the least advantaged person owns all. We then search for the value of $\omega$ that achieves the social state in which the difference principle is satisfied.

The reason why citizen 1 is the more "talented" or better-endowed person is that he/she has a "production function" specified by a function with an externality that satisfies the conditions (Hom) and (Mon)

$$
f(z ; \omega)=\alpha \omega^{\kappa} z,
$$

where $\alpha>0$ and $\kappa \geq 0$ are constants, and $z$ is the value of the input to pro${ }^{6}$ This term was borrowed from Rawls [1] [2] [5]. It is well known that Rawls repeatedly emphasized that the original position of Justice as Fairness was as a device of representation. 
duce the consumption good. This function was originally adopted by Chipman [10]. We also use this function here because it is easy to handle without any loss of essential points of discussion. However, our results do not depend upon this specific functional form (see Appendix). A natural interpretation for (2) is a potential ability such as natural talents. However, the production function (2) reflects the background institutions explained before; therefore, its interpretation should not be restricted to natural talents. Instead, it will include one's own environmental elements such as family and education. As to the latter, while opportunities in education are certainly open to all citizens in liberal societies, they must choose (and be chosen by) an appropriate school (consider schools of law, medicine, engineering, and music). The production function in this case results from a combination of one's natural talent and school education. Indeed, educational systems are a good example of institutions for information transmission or knowledge spillover of a Romer type.

When citizen 1 acts as a "producer", he/she takes the value of $\omega$ as a parameter, which means that it is given to him/her; therefore, he/she will subjectively produce under constant returns to scale. Here the role of "primary good" is threefold; it not only serves as an input commodity in the usual sense, but also develops the ability of citizen 1 which works through the background institutions and enters the model as a positive external effect, and finally it is used as "money" to purchase the consumption good. As stated, positive externalities, as well as market trades, convey an idea of reciprocity. The value of $\kappa$ is the degree of reciprocity. As citizen 1 is a representative agent of the class of talented people, the share value of $\omega$ included in the production function is also the value of the other members of the class represented by citizen 1 . The functional form (2) restricts the range of the externality (mutual advantage) to the group of talented persons.

We set up a political and cooperative scheme for this society as follows. Suppose that the entire amount $\Omega$ of the primary good is initially owned by citizen 2. Other initial distributions of the primary good are discussed in the following section. The "government" levies a tax $\omega$ on this and redistributes it to citizen 1 . As there is initially no consumption good, the less-endowed citizen 2 must give some amount of the primary good to the better-endowed citizen 1 to help him/her produce the consumption good. Using the remainder of the primary commodity (disposable income), citizen 2 purchases the consumption good in the market. In contrast, citizen 1 can undertake production activity only when some amount of the primary commodity $\omega>0$ is supplied by society (government), otherwise they can produce nothing given Equation (2). The difference principle requires $\omega$ to be set, which maximizes the consumption (welfare level) of citizen 2 at the equilibrium. Obviously, this sort of "fiscal policy" is realizable in property-owing democracies and liberal socialism regimes.

\section{Economic Conditions for the Difference Principle}

Let $p$ be the price of the consumption good and we normalize the price $q$ of the 
primary good as $q=1$. Given the primary good is not consumed, we can set $z=\Omega$ at the equilibrium. The competitive equilibrium of this economy is then easily obtained from the budget equations

$$
\begin{gathered}
p x_{1}=p \alpha \omega^{\kappa} z-z+\omega, \\
p x_{2}=\Omega-\omega,
\end{gathered}
$$

where $x_{1}$ is the consumption level of citizen 1 and $x_{2}$ is that of citizen 2 and the market condition

$$
x_{1}+x_{2}=\alpha \omega^{\kappa} \Omega .
$$

Given the production function $f(z ; \omega)$ is (subjectively) constant returns to scale, it follows from the profit condition that $p \alpha \omega^{K}=1$. Therefore, the equilibrium price is

$$
p=1 / \alpha \omega^{\kappa},
$$

and the equilibrium consumption levels are

$$
\left(x_{1}, x_{2}\right)=\left(\alpha \omega^{\kappa+1}, \alpha \omega^{\kappa}(\Omega-\omega)\right) .
$$

Normally, we would expect that $x_{1} \geq x_{2}$, but not always (see below). Eliminating $\omega$ from equation (3), we obtain

$$
\left(\frac{x_{1}+x_{2}}{\alpha \Omega}\right)^{\kappa+1}=\left(\frac{x_{1}}{\alpha}\right)^{\kappa}
$$

which is the locus of equilibria depicted for $\kappa=2$ in Figure 2. We refer to the curve (8) as the equilibrium curve.

The fundamental properties of the equilibrium curve are stated in the following theorem.

Theorem 1 For $\kappa>0$, the equilibrium curve starts from the origin when $\omega=0$, intersects with the $45^{\circ}$ line when $\omega=\Omega / 2$ and ends at the $x_{1}$-axis, $x_{1}=\alpha \Omega^{k+1}$ when $\omega=\Omega$. Moreover, it is concave to the $x_{1}$-axis and has a peak at $x_{1}=\alpha(\kappa \Omega /(\kappa+1))^{k+1}$ when $\omega=\kappa \Omega /(\kappa+1)$.

Proof. The first three properties are verified by substituting $0, \Omega / 2$, and $\Omega$ for $\omega$, respectively. We then obtain

$$
\frac{\mathrm{d} x_{1}}{\mathrm{~d} \omega}=\alpha(\kappa+1) \omega^{\kappa}, \frac{\mathrm{d} x_{2}}{\mathrm{~d} \omega}=\alpha \omega^{\kappa-1}(\kappa \Omega-(\kappa+1) \omega) .
$$

It follows from (9) that

$$
\begin{gathered}
\frac{\mathrm{d} x_{2}}{\mathrm{~d} x_{1}}=\frac{\kappa \Omega-(\kappa+1) \omega}{(\kappa+1) \omega}, \\
\frac{\mathrm{d}^{2} x_{2}}{\mathrm{~d} x_{1}^{2}}=\left(\frac{\mathrm{d} x_{1}}{\mathrm{~d} \omega}\right)^{-1} \frac{\mathrm{d}}{\mathrm{d} \omega}\left(\frac{\mathrm{d} x_{2}}{\mathrm{~d} x_{1}}\right)=\frac{-\kappa \Omega}{\alpha(\kappa+1)^{2} \omega^{\kappa+2}}<0 .
\end{gathered}
$$

Theorem 1 follows from (10) and (11).

We note that Theorem 1 (and Theorems 2 and 3 below) can be extended to general cases using conditions (Hom) and (Mon). In particular, the intersection 


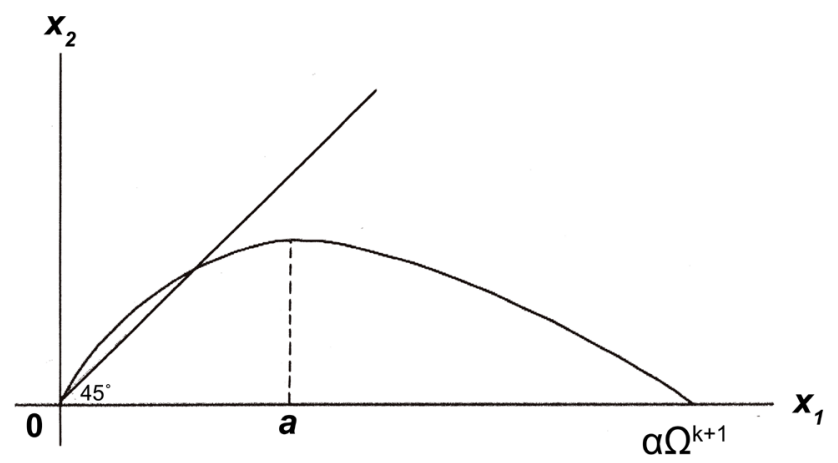

Figure 2. Equilibrium curve for $\kappa>1$.

property with the curve and the $45^{\circ}$ line at $\omega=\Omega / 2$ generally follows from the condition (Hom) rather than the specific functional form in the current model. See the proof of Theorem 4 in the Appendix.

Suppose for a moment that the degree of reciprocity $\kappa$ is greater than one (see Figure 2). The relation between the contribution curve OP in Rawls and the equilibrium curve (8) is explained as follows. As we mentioned earlier, Rawls sets the origin as the reference point where each individual is assigned the same amount of the primary good.

The point $\mathrm{O}$, the origin, represents the hypothetical state in which all social primary goods are distributed equally ([1], p. 76).

Thus, the point at which the equilibrium curve intersects the $45^{\circ}$ line corresponds to the origin $O$ in Figure 1, since by Theorem 1, we have $\omega=\Omega / 2$ at that point. The difference principle is applied to the equilibrium (7), thereby instructing society (or the government) how to set the value of $\omega$ to obtain the largest value of $X_{2}$.

If $\kappa>1$, this state can be achieved at $\omega=\kappa \Omega(\kappa+1)^{-1}$ by Theorem 1 and the equilibrium allocation permitted as just for this case is given by:

$$
\left(x_{1}, x_{2}\right)=\left(\alpha\left(\frac{\kappa \Omega}{\kappa+1}\right)^{\kappa+1}, \frac{\alpha}{\kappa}\left(\frac{\kappa \Omega}{\kappa+1}\right)^{\kappa+1}\right) \text {. }
$$

The value of $X_{1}$ is indicated by $a=\alpha(\kappa \Omega /(\kappa+1))^{\kappa+1}$ in Figure 2 .

What about the case where $\kappa \leq 1$ ? In this case, point $a$ in Figure 3 is placed to the left of the $45^{\circ}$ line. If point $a$ is chosen, this means that talented person 1 is "sacrificed" for society. Obviously, this is unjust. In this case, therefore, the difference principle would order the point on the $45^{\circ}$ line. The idea behind this observation is as follows. We always start from the reference point of $\omega=\Omega / 2$. Any deviation from this point is admitted only when both of the more- and less-advantaged persons gain by this deviation, which will be possible under the condition $\kappa>1$. In other words, the difference principle will order the states that are distinct from that of perfect equality only for those societies where reciprocity works sufficiently or the degree of reciprocity is greater than one. Rawls stated: 


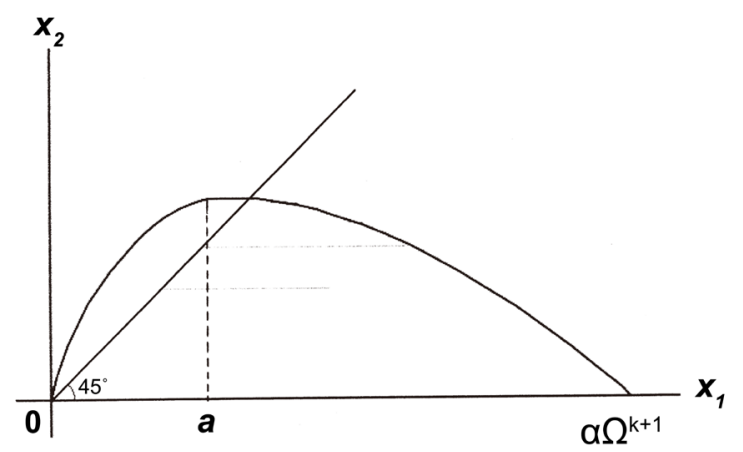

Figure 3. Equilibrium curve for $\kappa<1$.

[T] he difference principle is a strongly egalitarian condition in the sense that unless there is a distribution that makes both persons better off (limiting ourselves to the two person case for simplicity), an equal distribution is to be preferred. The [social] indifference curves [...] are actually made up of vertical and straight [horizontal] lines that intersect at right angles at the $45^{\circ}$ line (again supposing an intertemporal and cardinal interpretations of the axes). No matter how much either person's situation is improved, there is no gain from the standpoint of the indifference principle unless the other gains too ([1], p. 76).

We summarize these results as a theorem.

Theorem 2 The difference principle orders the allocation associated with $\omega=\kappa \Omega /(\kappa+1)$ on equilibrium curve when $\kappa>1$, and the allocation on the $45^{\circ}$ line $(\omega=\Omega / 2)$ when $0<\kappa \leq 1$.

For the following analysis, we need to distinguish two concepts of optimality. The first concept is the standard notion of Pareto optimality:

Definition 1 A feasible allocation $\left(x_{1}, x_{2}\right)$, which satisfies the Equation (5) is said to be globally Pareto optimal (or Pareto optimal for short), if and only another feasible allocation exists $\left(y_{1}, y_{2}\right)$ such that $\left(x_{1}, x_{2}\right)<\left(y_{1}, y_{2}\right)^{7}$.

Notice that globally Pareto optimal allocations are exactly the ones which satisfy $x_{1}+x_{2}=\alpha \Omega^{\kappa+1}$. Our second concept of optimality is a local one, defined only for the equilibrium allocations:

Definition 2 An equilibrium allocation $\left(x_{1}, x_{2}\right)$, which satisfies the equation (8) is said to be locally Pareto optimal (or locally optimal for short), if and only if the derivative $\mathrm{d} x_{2} / \mathrm{d} x_{1}$ is less than or equal to 0 at $\left(x_{1}, x_{2}\right)$.

Obviously the allocations on the equilibrium curve over the domain $a \leq x_{1} \leq \alpha \Omega^{\kappa+1}$ are locally optimal. Hence the allocation (11) stipulated by the difference principle for the case $\kappa>1$ is locally optimal. Rawls was concerned with local optimality when he discussed the efficiency of allocations [1]. We trust that the local optimality is more appropriate than the global one for liberal societies, given the latter will generally need to compare very distant allocations.

${ }^{7}\left(x_{1}, x_{2}\right) \leq\left(y_{1}, y_{2}\right)$ is defined by $x_{1} \leq y_{1}$ and $x_{2} \leq y_{2}$. We then define $\left(x_{1}, x_{2}\right)<\left(y_{1}, y_{2}\right)$ by $\left(x_{1}, x_{2}\right) \leq\left(y_{1}, y_{2}\right)$ and $\left(x_{1}, x_{2}\right) \neq\left(y_{1}, y_{2}\right)$. 
To attain an improving allocation, the society must gather all produced commodities at once and redistribute them among citizens. Although such drastic reallocations might be possible in societies with centrally planned economies, they would be unrealistic for liberal societies with market economies.

Next, we would like to identify allocations determined by the utilitarian principle that select the equilibrium allocations maximizing total (average) utility $x_{1}+x_{2}$. For this, the relevant statements in Rawls are:

If there are but two persons, then assuming an interpersonal cardinal interpretation of the axes, the utilitarian's indifference lines for distributions are straight lines perpendicular to the $45^{\circ}$ line. [...] Drawing the same contribution curve OP as before, we see that the best distribution from a utilitarian point of view is reached at the point which is beyond the point $b$ where the OP curve reaches its maximum (ibid., p. 77).

Thus, we obtain a more precise result.

Theorem 3 For any value of $\kappa>0$, the utilitarian principle orders the allocation $\left(\alpha \Omega^{\kappa+1}, 0\right)$.

Proof. Computing the derivative, we have

$$
\frac{\mathrm{d} x_{2}}{\mathrm{~d} x_{1}}=\frac{\mathrm{d} x_{2} / \mathrm{d} \omega}{\mathrm{d} x_{1} / \mathrm{d} \omega}=\frac{\alpha \omega^{\kappa-1}(\kappa \Omega-(\kappa+1) \omega)}{\alpha(\kappa+1) \omega^{\kappa}}=\frac{\kappa \Omega-(\kappa+1) \omega}{(\kappa+1) \omega} .
$$

Then at $\omega=\Omega$, one has $\mathrm{d} x_{2} / \mathrm{d} x_{1}=-1 /(\kappa+1)>-1$ whenever $\kappa>0$. Given the equilibrium curve is concave to the $x_{1}$-axis, the whole curve is below the line $x_{1}+x_{2}=\alpha \Omega^{\kappa+1}$ and $\alpha \Omega^{\kappa+1}$ is the maximum value of total utility; see Figure 5. The result follows.

Theorem 3 might look surprising given it states that the utilitarian principle stipulates as just an allocation in which talented people monopolize all of society's wealth! It is interesting that the set of equilibrium allocations that are globally Pareto optimal is just $\left(\alpha \Omega^{\kappa+1}, 0\right)$ because every other point on the equilibrium curve can be moved to an optimal point on $x_{1}+x_{2}=\alpha \Omega^{\kappa+1}$, which is located at its north-east direction (see Figure 5). However, we cannot help but hold quite strong skepticism about the utilitarian principle as a principle of justice for societies with any degree of reciprocity, even if Pareto optimal allocations are realized by it. Indeed, Theorem 3 might be considered as yet another reason for the justification of the difference principle over the utilitarian principle from the original discussion.

Rawls remarked on the slope of the utilitarian indifference line:

However, since $x_{1}$ and $x_{2}$ are representative men, their gains must be weighted by the number of persons that they each represent. Since presumably $x_{2}$ represents rather more persons than $x_{1}$, the indifference line become more horizontal, as seen in Figure 8 [Figure 4] (ibid., p. 77).

In the Appendix, we show that Theorem 3 is true even if this remark is considered (Theorem 6). 


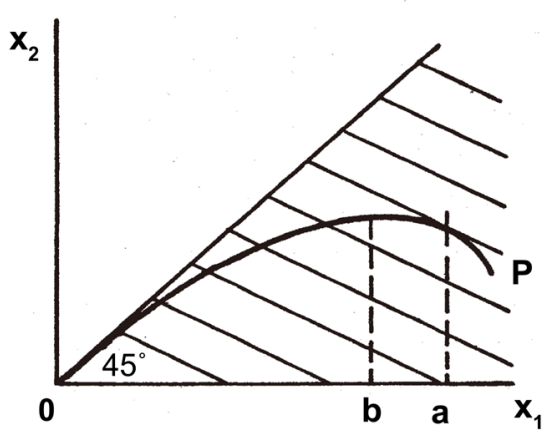

Figure 4. Figure 8 in Theory, p.77.

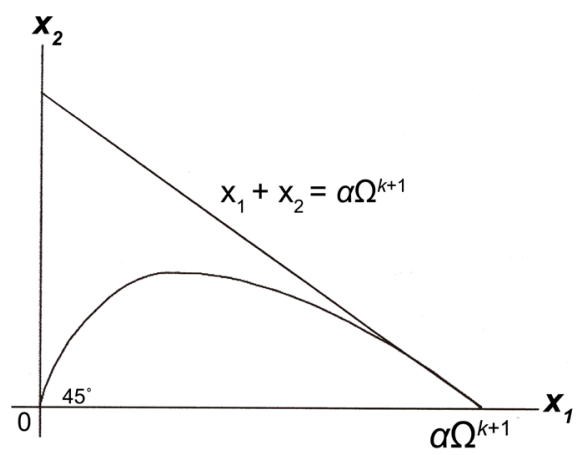

Figure 5. Utilitarian principle.

Finally, we consider the case $\kappa=0$ (no externalities). This economy might appear in a standard microeconomics textbook. Then equation (8) simply reduces to the market condition, which is the (usual) utility possibility frontier:

$$
x_{1}+x_{2}=\alpha \Omega \text {. }
$$

That is, we have only the pure trade-off between the consumption of both consumers. In this case, contribution curves like OP do not appear. For the curve to have the upward portion, some sort of mechanism is required, such as externalities, which are considered to represent social cooperation rendering mutual advantage. Rawls's understanding of this point was exact. Recall his statement:

Note that the contribution curve, the curve OP, supposes that social cooperation defined by the basic structure is mutually advantageous. It is no longer a matter of shuffling about a fixed stock of goods (ibid., p. 77).

The lack of social cooperation mechanisms is exactly why any insights for determining just allocations cannot be obtained from standard market models without externalities. In such models, the difference principle will mechanically order the perfect equality $x_{1}=x_{2}=\alpha \Omega / 2$ as the intersection of the curve (14) with the $45^{\circ}$ line. Thus, the difference principle is simply reduced to the perfect equality principle. However, the utilitarian principle is indifferent between every allocation on the utility possibility frontier (14). It does not select any specific allocations as just when the commodity is produced under constant returns to 
scale.

\section{Political Conditions for the Difference Principle}

In previous sections, we have described a model of liberal societies, which was absent from Rawls's original discussions. In the model, each realization of a social state is determined by the policy parameter $\omega$, which is citizen 1's share of the primary good. Given these institutional and political mechanisms for the difference principle provided by our model, we can now proceed to discuss the political conditions for the difference principle to be satisfied in socially stable ways.

Up to this point, we have assumed that citizen 2 initially owned the complete resource, on which the citizen was taxed by the government. The citizen would do so whenever he or she is rational because the tax will be used to make them better off. In contrast, consider the situation where the whole of the resource is initially owned by citizen 1 . In this case, the government must also collect taxes to achieve the allocation ordered by the difference principle. How is this possible?

It seems difficult to assume that the citizen will agree to pay the tax voluntarily if he or she is only rational, as is usually assumed in ordinary economic market theory. The government will be able to collect money only through some law that coerces the citizens to pay taxes. For the citizens to endorse this law, the difference principle must necessarily be already accepted in society as a principle of justice. The citizens must also be convinced that the government's fiscal policy will execute the difference principle. Further, citizens must hold these facts as public information. Those conditions coincide essentially with the first two conditions for a well-ordered society raised by Rawls:

To say that a society is well-ordered conveys three things; first (and implied by the idea of a publicly recognized conception of justice), it is a society in which everyone accepts, and knows that everyone else accepts, the very same principles of justice; and second (implied by the idea of the effective regulation such a conception), its basic structure-that is, its main political and social institutions and how they fit together as one system of cooperation-is publicly known, or with good reason believed, to satisfy these principles ([5], p. 35).

Rawls required a third condition for society to comply with social rules:

And third, its citizens have a normally effective sense of justice and so they generally comply with society's basic institutions, which they regard as just (ibid., p. 35).

However, for this condition to be satisfied, it seems insufficient that the citizens are simply rational. Instead, we must consider that they are reasonable. That is, citizens are ready to propose principles and standards as fair terms of cooperation and to abide by them willingly, given the assurance that others will 
likewise do so (ibid., p. 49). We recall that the "productivity" of citizen 1 is increased by external effects from background institutions, which means that they owe the improvement of their abilities to society. This yields fair terms of cooperation in Rawls's sense:

[... W]e cannot view the talents and abilities of individuals as fixed natural gifts. To be sure, even as realized there is presumably a significant genetic component. However, these abilities and talents cannot come to fruition apart from social conditions, and as realized they always but one of many possible forms. Developed natural capacities are always a selection, a small selection at that, from the possibilities that might have been attained (ibid., pp. 269-70).

Thus, if the citizens were reasonable, they would realize that the current situation where rich people monopolize all of the social resources and wealth is unjust ${ }^{8}$. Moreover, they would endorse Rawls's thesis concerning natural talents as a common asset [1]. Consequently, they would agree with his following statement:

Here it is crucial that the difference principle includes an idea of reciprocity: the better endowed (who have a more fortunate place in the distribution of native endowments they do not morally deserve) are encouraged to acquire still further benefits-they are already benefited by their fortunate place in the distribution-on condition that they train their native endowments and use them in ways that contribute to the good of the less endowed (whose less fortunate place in the distribution they also do not morally deserve) ([2], pp. 76-77).

Rawls concluded:

In such a [well-ordered] society the publicly recognized conception of justice establishes a shared point of view from which citizens' claims on society can be adjudicated ${ }^{9}$ ([5], p. 35).

Following Rawls, we also conclude that under those conditions, the difference principle will be effective as a principle of justice for regulating the economic differences in a society characterized by property-owing democracy or liberal socialism.

\section{Conclusions}

1) The main contribution of this paper is that it clarifies the mechanism of implementing the difference principle and enhances the economic and political conditions required for that principle. However, this paper is just a starting point for investigations. For instance, we have assumed that there are the only two groups-advantaged and less advantaged-of citizens in our society. Future

${ }^{8}$ However, we notice that this state is Pareto optimal.

${ }^{9}$ For a more precise exposition, see Rawls [1], pp. 48-50. 
studies should explore the more complex effects working among several groups, such as "chain connection," described by Rawls [1] (see also 3 below).

2) For simplicity, we have discussed the economic conditions under the assumption that the production function is of the form $f(z, \omega)=\alpha \omega^{\kappa} z$. However, our economic discussions do not depend on any specific functional form and will essentially hold under the conditions (Hom) and (Mon) for completely general settings. In other words, the class of production functions representing the difference principle is exactly characterized by functions with externalities that satisfy these two conditions. Moreover, our theorems hold for models with any arbitrary population ratio. We illustrate this general discussion in the Appendix.

3) The difference principle concerns economic inequality. Economic markets are the cause of this difference and a means to regulate it. Therefore, economic theory is required. In this paper, we presented an example of such a market model with the assistance of a purely economic concept in the form of external increasing returns.

Conversely, the difference principle is also a principle of justice. Thus, some political and philosophical considerations that surpass theoretical economic thinking are also required. To obtain positive results, we presented a sociopolitical model (which is the same as the market model). The results, if any, must be confirmed by the test of reflective equilibrium. That is, how well this perspective articulates our more considered convictions of political justice at all levels of generality after due examination once all adjustments and revisions that seem compelling have been made ([5], p. 28). We trust that our conclusion in the preceding section passed this test.

It goes without saying that the actual society is far more complex than the toy model described in the previous section, which ignored many economic and political aspects. Therefore, a concern could be that citizens must consider how every political and economic matter affects the prospects of the least-advantaged people, to which Rawls responded:

A useful reply is this: we are to proceed by selecting a few instruments, as we may call them, that can be adjusted so as to meet the difference principle, once the whole family of policies is given ([2], p. 161).

In our simplified society, we highlighted a tax-subsidy policy, but there are obviously many other welfare policies in the actual society.

Nonetheless, the production function as a natural endowment of citizen 1 is notably generally unobservable by others, including the government; therefore, the production function would not be able to compute the equilibrium and the optimal value of $\omega$. In response, we restate that the purpose of our model is to develop an intuition and understanding of the implementation of the difference principle, confirm that the fulfillment of the principle is indeed possible, and also confirm that the conditions given in the preceding section are sufficient (but not necessary) conditions for the difference principle. 
Unlike with the first principle, we should also consider that it is generally difficult in an actual society to judge whether the second principle is fulfilled. Rawls admitted as much:

Whether the aims of the second principle are realized is far more difficult [than the first principle] to ascertain. To some degree these matters are always to open to reasonable differences of opinion; they depend on inference and judgement in assessing complex social and economic information (ibid., p. 162).

Therefore, Rawls recommended that the difference principle be excluded from the essentials for a constitution ([2], p. 49). We also agree with this opinion. Nevertheless, Rawls also said that equality in democracies requires something like the difference principle:

While the difference principle does not fall under the constitutional essentials, it is nevertheless important to try to identify the idea of equality most appropriate to citizens viewed as free and equal, and as normally and fully cooperating members of society over a complete life. I believe this idea involves reciprocity at the deepest level and thus democratic equality properly understood requires something like the difference principle (ibid., p. 49).

We have nothing further to add to this statement.

\section{Acknowledgements}

An earlier version of this paper was presented at the 76th annual meeting of the Philosophical Association of Japan held at Hitotsubashi University, May 20, 2017. I would like to thank the session participants. This research is supported by Grants-in-Aid for Scientific Research (No. 15K03362) from the Ministry of Education, Culture, Sports, Science and Technology, Japan.

\section{References}

[1] Rawls, J. (1971) A Theory of Justice. Harvard University Press, Cambridge.

[2] Rawls, J. (2001) Justice as Fairness: A Restatement. Harvard University Press, Cambridge.

[3] Hayek, F.A. (1944) The Road to Serfdom. Routledge \& Kegan Paul, London.

[4] Nozick, R. (1974) Anarchy, State and Utopia. Basic Books, New York.

[5] Rawls, J. (1993) Political Liberalism. Columbia University Press, New York.

[6] Smith, A. (1776/1976) The Wealth of Nations. University of Chicago Press, Chicago.

[7] Romer, P. (1986) Increasing Returns and Economic Growth. Journal of Political Economy, 94, 1002-1037. https://doi.org/10.1086/261420

[8] Young, A. (1928) Increasing Returns and Economic Progress. Economic Journal, 38, 527-542. https://doi.org/10.2307/2224097

[9] Arrow, K.J. (1973) Some Ordinalist-Utilitarian Notes on Rawls's Theory of Justice. The Journal of Philosophy, 70, 245-263. https://doi.org/10.2307/2025006 
[10] Chipman, J.S. (1970) External Economies of Scale and Competitive Equilibrium. Quarterly Journal of Economics, 84, 347-385. https://doi.org/10.2307/1879425

[11] Suzuki, T. (2009) General Equilibrium Analysis of Production and Increasing Returns. World Scientific, Singapore.

[12] Suzuki, T. (2016) Welfare Analysis of a Market Model with External Increasing Returns and Differentiated Commodities. Theoretical Economics Letters, 7, 63-78. https://doi.org/10.4236/tel.2017.71007 


\section{Appendix}

For notational convenience, we set $f(1, \omega)=\phi(\omega)$ and assume $\phi(\omega)$ to be twice-continuously differentiable. We also assume that $\phi(0)=0$, or that no outputs can be produced without the primary good. Note that the condition (Mon) implies that $\phi^{\prime}(\omega)>0$. Suppose that there are $n_{1}$ citizens of group 1 and $n_{2}$ citizens of group 2, and assume that each member of group 1 own the same amount of initial endowment $\omega_{1}$, and similarly citizens are endowed with $\omega_{2}$ in group 2; hence we have $n_{1} \omega_{1}+n_{2} \omega_{2}=\Omega$. Let $\theta=n_{1} / n_{2}$ be the population ratio, and we denote $\Omega_{1}=\Omega / n_{1}$ and $\Omega_{2}=\Omega / n_{2}$; then it follows that

$$
\theta \omega_{1}+\omega_{2}=\Omega_{2} \text {. }
$$

The market equilibrium is now determined by the following equations:

$$
\begin{gathered}
p x_{1}=p \phi\left(\omega_{1}\right) z-z+\omega_{1}, \\
p x_{2}=\omega_{2},
\end{gathered}
$$

and

$$
\theta x_{1}+x_{2}=\theta \phi\left(\omega_{1}\right) \Omega_{1}
$$

As before, the equilibrium price is determined as $p=1 / \phi\left(\omega_{1}\right)$. Hence, the derivatives are calculated as

$$
\frac{\mathrm{d} x_{1}}{\mathrm{~d} \omega_{1}}=\phi^{\prime}\left(\omega_{1}\right) \omega_{1}+\phi\left(\omega_{1}\right), \frac{\mathrm{d} x_{2}}{\mathrm{~d} \omega_{1}}=\phi^{\prime}\left(\omega_{1}\right)\left(\Omega_{2}-\theta \omega_{1}\right)-\theta \phi\left(\omega_{1}\right) .
$$

The equilibrium curve $\Phi\left(x_{1}, x_{2}\right)=0$ is obtained by eliminating $p, \omega_{1}$, and $\omega_{2}$ from (15) to (18). Theorem 1 is now generalized to:

Theorem 4 The equilibrium curve starts from the origin when $\omega_{1}=0$, intersects with the $45^{\circ}$ line when $\omega_{1}=\omega_{2}$ and ends at the $x_{1}$-axis, $x_{1}=\phi\left(\Omega_{1}\right) \Omega_{1}$ when $\omega_{1}=\Omega_{1}$. Moreover, it is concave to the $x_{1}$-axis if

$$
\phi^{\prime \prime}\left(\omega_{1}\right) \phi\left(\omega_{1}\right)<2 \phi^{\prime 2}\left(\omega_{1}\right)
$$

and has the peak at $x_{1}=\phi(\hat{\omega}) \hat{\omega}$ where $\hat{\omega}$ satisfies

$$
\phi^{\prime}(\hat{\omega})\left(\Omega_{2}-\theta \hat{\omega}\right)-\theta \phi(\hat{\omega})=0 .
$$

Proof. The first three properties are verified by substituting $0, \Omega / 2$, and $\Omega$ for $\omega$ in (15), (16), and (17), respectively. We notice that the intersection of the curve with the $45^{\circ}$ line at $\omega=\Omega / 2$ comes from the condition (Hom). Given the "profit" of citizen 1 is 0 , her income to purchase the consumption good is solely determined by her initial endowment; therefore, citizens 1 and 2 will purchase the same amount when $\omega_{1}=\omega_{2}$. From (19), we can compute the following equations:

$$
\begin{aligned}
\frac{\mathrm{d} x_{2}}{\mathrm{~d} x_{1}} & =\frac{\phi^{\prime}\left(\omega_{1}\right)\left(\Omega_{2}-\theta \omega_{1}\right)-\theta \phi\left(\omega_{1}\right)}{\phi^{\prime}\left(\omega_{1}\right) \omega_{1}+\phi\left(\omega_{1}\right)}, \\
\frac{\mathrm{d}^{2} x_{2}}{\mathrm{~d} x_{1}^{2}} & =\frac{\left(\phi^{\prime \prime}\left(\omega_{1}\right) \phi\left(\omega_{1}\right)-2 \phi^{\prime 2}\left(\omega_{1}\right)\right) \Omega_{2}}{\left(\phi^{\prime}\left(\omega_{1}\right) \omega_{1}+\phi\left(\omega_{1}\right)\right)^{3}} .
\end{aligned}
$$


The value of $x_{1}$ which attains the peak of $\Phi\left(x_{1}, x_{2}\right)=0$ and the concavity of the curve follow from (22) and (23), respectively.

Note that the concavity condition (20) is mild and does not depend on $\theta$.

In general, no counterpart to the degree of reciprocity $\kappa$ exists. Instead, we obtain a measure of reciprocity from the derivative of the equilibrium curve on the $45^{\circ}$ degree line.

Definition 3 We say that reciprocity works effectively or reciprocity is effective if and only if $\mathrm{d} x_{2} / \mathrm{d} x_{1}>0$ when $\omega_{1}=\omega_{2}$.

By (22), reciprocity is effective if and only if

$$
\phi^{\prime}\left(\left(n_{1}+n_{2}\right)^{-1} \Omega\right)\left(n_{1}+n_{2}\right)^{-1} \Omega-\theta \phi\left(\left(n_{1}+n_{2}\right)^{-1} \Omega\right)>0 .
$$

It is easy to see in particular that for $f(z, \omega)=\alpha \omega^{\kappa} z$, reciprocity is effective if and only if $\kappa>\theta$. It is interesting that the smaller the proportion of the advantaged (talented) persons, the more likely the reciprocity is to be effective.

The next theorem is immediately drawn from Theorem 4.

Theorem 5 Suppose that reciprocity works effectively. Then the difference principle orders the allocation associated with $\omega=\hat{\omega}$ on equilibrium curve with $x_{1}>x_{2}$, where $\hat{\omega}$ is a solution of the equation (21).

Note that we do not assume the concavity condition (20) in Theorem 5. Finally, we state a generalization of Theorem 3.

Theorem 6 Suppose that the concavity condition (20) holds. Then the average utilitarian principle orders the allocation $\left(\phi\left(\Omega_{1}\right) \Omega_{1}, 0\right)$ for any $\theta>0$.

Proof. We first notice that the average utilitarian principle orders to maximize $\theta x_{1}+x_{2}$. Set $\omega_{1}=\Omega_{1}$ in (22). Then we have $\theta \omega_{1}=\Omega_{2}$; therefore, it follows that

$$
\left.\frac{\mathrm{d} x_{2}}{\mathrm{~d} x_{1}}\right|_{\omega_{1}=\Omega_{1}}=\frac{-\theta \phi\left(\Omega_{1}\right)}{\phi^{\prime}\left(\Omega_{1}\right) \Omega_{1}+\phi\left(\Omega_{1}\right)}>-\theta .
$$

Given the equilibrium curve is concave to the horizontal axis, the result follows as in Theorem 3. 